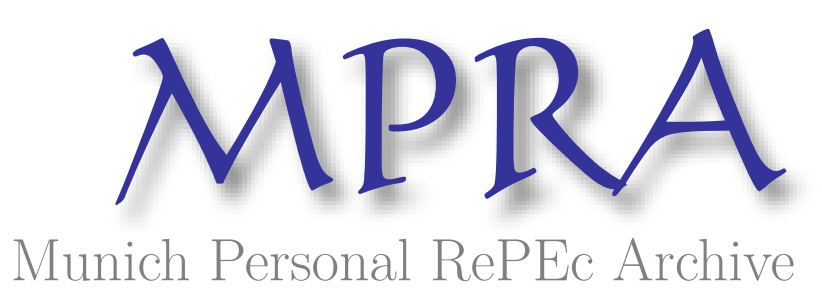

\title{
Choosing a Retirement Income Strategy: Outcome Measures and Best Practices
}

Pfau, Wade Donald

31 May 2012

Online at https://mpra.ub.uni-muenchen.de/39145/

MPRA Paper No. 39145, posted 31 May 2012 10:04 UTC 


\title{
Choosing a Retirement Income Strategy: Outcome Measures and Best Practices
}

\author{
by \\ Wade D. Pfau \\ Associate Professor \\ National Graduate Institute for Policy Studies (GRIPS) \\ 7-22-1 Roppongi, Minato-ku, Tokyo 106-8677 Japan \\ Email: wpfau@grips.ac.jp \\ phone: 81-3-6439-6225
}

\begin{abstract}
The race is on to build frameworks to evaluate retirement income strategies for clients facing various post-retirement circumstances. Retirement income planning is a complicated process in which clients must balance competing tradeoffs (maximize spending, protect from income shortfalls, leave a bequest) over an uncertain lifespan. After providing an overview of the basic building blocks of retirement income strategies, this article seeks to explain best practices, highlight potential missteps and problems which may arise, clarify areas where controversies and disagreements remain, and suggest further enhancements and modifications to make retirement income frameworks as useful as possible. The best practices described here include a description of the approaches and products to be included in a complete framework, the use of simulations or scenario testing as a way to understand how strategies respond in a variety of market circumstances, the need to connect asset market return assumptions to current market conditions rather than historical averages, the need to apply consistent fees across strategies, the need to distinguish how outcomes will differ when using either survival probabilities or fixed horizons, and other matters. The article concludes with a discussion of evaluation criteria, which can be subdivided into three general groupings. These include measures focusing on downside spending in bad luck cases, measures focusing on overall or upside spending or translating spending into the value it provides, and measures taking into account remaining assets at the end of the retirement period.
\end{abstract}

JEL Codes: D14

Keywords: retirement planning, retirement income modeling

Acknowledgements: Many individuals provided me with useful feedback and discussions about the topics in this article. In particular, I wish to thank Jason Branning, Michael Finke, Francois Gadenne, Michael Kitces, Manish Malhotra, Steve Mitchell, Robert Powell, Dick Purcell, Bob Seawright, Joe Tomlinson, Duncan Williams, and Michael Zwecher. I am grateful for financial support from the Japan Society for the Promotion of Science Grants-in-Aid for Young Scientists (B) \# 23730272. 


\section{Introduction}

Researchers, planners, and companies are now working to develop and build robust frameworks to describe, compare, and optimize strategies for retirement distribution. An important function of the Retirement Income Industry Association (RIIA) and the Retirement Management Journal (RMJ) is to provide a forum to discuss and evaluate such efforts as part of RIIA's mission to create an Empirical Validation Framework. We can search for best practices, highlight potential missteps and problems which may arise, clarify areas where controversies and disagreements remain, and suggest further enhancements and modifications to make these frameworks as useful as possible, with an emphasis on process rather than products, for a broad diversity of clients.

Traditionally, risk tolerance in the accumulation phase builds on the tools of Modern Portfolio Theory (MPT) and portfolio diversification to find a suitable balance between expected investment returns and the volatility of those returns. Investors seek strategies that will support the highest expected wealth subject to the investor's tolerance and capacity to endure downward fluctuations in the portfolio value. But this was never the complete story. Household investors have particular goals in mind, such as supporting a desired spending level throughout retirement, which should be considered when building accumulation-based investment strategies. Life-cycle finance suggests that the lifetime income stream supportable with all assets (including financial, social, and human capital) is a more suitable metric than accumulated financial wealth. Financial wealth accumulation is also not an entirely suitable metric as the income stream it will support varies with fluctuating interest rates and market conditions.

The issues faced in retirement distribution are even more complicated and extend well beyond the limits of MPT. Markowitz (1991) wrote about how personal finance must be studied with multiple period game-of-life simulations, rather than single-period wealth accumulation. This is now common knowledge in the field. For individual retirees, the objective is to obtain sustainable cash flows over an uncertain time period. To achieve this, retirees may draw not just from their financial capital, but also social and human capital. Retirees only receive one shot to obtain sustainable cash flows from their savings (one whack at the cat, as Zwecher (2012) puts it) and must develop a strategy which will at least meet basic needs no matter the length of life or the sequence of post-retirement market returns and inflation. Retirees have little leeway for error, as returning to the labor force may not be a realistic option.

The goals and desires of retirees are paramount. Almost universally, retiree goals include building an opportunity to obtain a relatively consistent income stream for life, avoiding the depletion of financial wealth or having to make significant spending cuts, possibly leaving a bequest, and maintaining control and flexibility for one's savings. Some 
analysts also make effort to incorporate goals of a more behavioral nature, such as the observation by Evensky (2006) that clients want their retirement paychecks to come from clearly visible and reliable sources separate from the main investment portfolio.

Retirees, indeed, face a complex optimization problem to find the proper balance between many goals over an uncertain lifespan. To meet essential and discretionary spending goals, underfunded and constrained retirees will seek to spend as much as possible while keeping close watch over the chances for having to make unacceptable cuts to their retirement budget. While annuities, with their pooling of mortality risk, may provide a solution to maximize spending potential in the face of uncertain lifespans, many retirees seem loath to sacrifice control over their hard-earned savings. Optimizing among all these complex and uncertain tradeoffs is challenging to say the least. Meanwhile, retirees must also deal with an assortment of behavioral quirks which impede good decision making. Advice from caring and knowledgeable retirement professionals who are guided by a well-vetted underlying process is needed.

For the basis of such advice, a cutting-edge retirement income framework must be able to translate client goals, needs, and desires into an appropriate product and asset allocation strategy. The process must delve into the complexities of retirement income to allow clients to consider optimal retirement income strategies: how much retirement income is feasible, how to best spread spending power over the course of retirement, how to allocate among various products differing in the amount of control and guarantees provided, and how to choose an asset allocation for the portion of wealth to be used with systematic withdrawals. This article explores some of the important issues which serve as a backdrop to the retirement income process.

\section{A Brief Overview of Retirement Income Building Blocks}

A practical starting point for discussing retirement income strategies is Bengen (2006). There he collects and updates his research findings since 1994 on the subject of "safe" withdrawal rates. Though his work is based only on U.S. data since 1926 (a relatively short and rather exceptional period in world history), Bengen provides a comprehensive analysis of systematic withdrawals to smooth consumption from a portfolio of volatile assets invested with a total returns perspective. Bengen's work introduces the SAFEMAX concept, which is the highest sustainable withdrawal rate from the worst-case scenario as determined from rolling historical periods. His original finding was that inflationadjusted withdrawals over a 30-year period could be supported in the worst-case scenario (which happened to a retiree in 1966) with a $4.15 \%$ initial withdrawal rate from retirement date assets. And thus we have what is known as the $4 \%$ rule. 
Bengen's research made the issue of sequence-of-returns risk clear to readers who may have otherwise thought about withdrawal rates using deterministic assumptions for stock returns. His recommended stock allocation for retirees was 50-75\%, as this historically provided greater upside potential while not having a noticeable impact on the SAFEMAX. Though acknowledgment is made that a new worst-case scenario is possible in the future and mid-course corrections may be needed, users of safe withdrawal rates generally treat $4 \%$ as a reasonably safe worst-case sustainable withdrawal rate for a 30 year retirement period. Bengen now speaks regularly about $4.5 \%$ as the safe withdrawal rate, a result derived from also including small-capitalization stocks into the portfolio mix.

Other research following along the lines of systematic withdrawals from volatile portfolios with a total returns focus include Guyton (2004), who develops decision rules to guide portfolio withdrawals in response to market fluctuations, and Pfau (2011a), who moves the focus to the savings rate that would have always supported one's desired retirement expenditures regardless of the wealth accumulation or implied required withdrawal rate at the retirement date.

Leaving behind the purely total returns perspective, other important works differ primarily because fixed income assets are held to maturity in order to guarantee upcoming retiree expenses over the short and/or medium term. More volatile assets with higher expected returns are then deployed to cover expenses for more distant time periods. This is time segmentation. Key examples of this approach include Basu (2005), Huxley and Burns (2005), and Evensky (2006). An underlying theme in these particular studies is that annuitization need not play an important role as asset/liability matching with bonds is used to meet upcoming expenses, providing a longer period for volatile assets to recover from market declines before they must be sold. Evensky (2006) extols the behavioral benefits of this process in helping clients to avoid panic during downturns; a five-year mantra (fixed income locks in spending needs over the next five years) helps clients to stay the course while waiting for market recovery.

Another shared trait among these studies is their support for a higher overall stock allocation relative to the total returns counterpart. Controversially, time diversification is evoked since spending needs over the shorter term are fixed with bond ladders. The controversy is that risk is properly defined as probability times magnitude, and though the probability of bad outcomes may decline with time, the severity of harm in the worst-case scenarios grows. Stocks are inherently risky, a point which is not always clear in the U.S. historical data as severe market drops were generally followed soon after by recoveries. Pfau (2011b) does highlight how the $4 \%$ rule tended to perform rather poorly in most other developed market countries and how the high market valuations and low bond 
yields in recent years could threaten the continued success of the $4 \%$ rule in the United States.

This provides a transition to other strategies which emphasize less volatile investments. For instance, Huebsher (2011) describes a safer safe withdrawal rate over a 30-year period by holding all financial wealth in a 30 -year TIPS. He uses Monte Carlo simulations for yield changes to account for interest rate risk as interest payments and the selling of principal are combined to meet each year's inflation-adjusted cash flow needs. Bodie and Clowes (2003) describe investing safely with inflation-protected bonds to meet essential expenses and then investing funds which a client can afford to lose in stock index call options or other risky assets. In the end, though, they note that "most investors should use TIPS and I Bonds alone" (page 120).

Bond ladders do expose clients to longevity risk should one happen to live past the ladder's end date. Shankar (2009) developed an alternative of combining a 20-year TIPS ladder with a deferred immediate annuity (DIA) that begins payments 20 years after the retirement date. This strategy could support a higher withdrawal rate, and it does reduce expenditures on annuities, though only nominal deferred immediate annuities can be purchased at present. Retirees are exposed to inflation risk if actual inflation differs from the current breakeven inflation rate implied by TIPS and nominal bond yields.

Single-premium immediate annuities (SPIAs), either in nominal or inflation-adjusted terms, present another option for retirees. An early important study in this area is Ameriks, Veres, and Warshawsky (2001), which introduced several key findings about the role of partial annuitization with nominal SPIAs. The authors do not try to optimize the portion of wealth to annuitize, but they do demonstrate that annuitizing 25 or $50 \%$ of wealth can help to improve the success rates for a $4.5 \%$ withdrawal rate. The chances for success increase, but the tradeoff is a tendency toward lower terminal wealth. These authors also demonstate how partial annuitization allows the remaining portfolio to be invested more aggressively without jeopardizing success.

Guaranteed Lifetime Withdrawal Benefit (GLWB) riders for variable annuities, also known as Guaranteed Minimum Withdrawal Benefits (GMWB), provide a seemingly attractive offer for retirees: they protect on the downside with a guaranteed income for life, they include upside potential with step-up features for growing markets, and they are contracts which can be ended with remaining assets returned. However, their guarantees are made only in nominal terms, and the step-up features can generally not be expected to keep up with inflation. Whether they provide suitable downside protection to justify their annual rider fee is a source of ongoing debate among researchers. 
Finally, human and social capital, including Social Security, part-time work, and any corporate defined-benefit pensions, may play an essential role in the retirement income strategies for many retirees. In particular, Social Security provides inflation-adjusted income for the remainder of one's life. Retirement benefits can begin as early as age 62, but benefits grow as one delays to age 70. Reichenstein and Meyer (2011) show it is often worthwhile as insurance against longevity risk to spend down other assets in order to delay the start of Social Security benefits. Getting this claiming decision right is quite important as the income floor provided by Social Security may serve as an essential source of retirement income for many clients.

\section{Best Practices for a State of the Art Model}

We can consider best practices and potential missteps in the collective efforts of those working to optimize retirement income strategies. As a starting point, a comprehensive framework should incorporate the Social Security claiming decision, various systematic withdrawal strategies from volatile portfolios, bond ladders, and retirement income products such as single-premium immediate annuities, variable annuities with guarantee riders, and deferred income annuities (also called longevity insurance). A complete framework would also incorporate other sources of human and social capital, time segmentation approaches, the option to delay or ladder annuity purchases, long-term care insurance, life insurance, reverse mortgages, home equity loans, and structured products based on derivatives to protect on the downside while maintaining some upside.

As well, modeling efforts must properly account for uncertainty. This may be accomplished with historical simulation or Monte Carlo simulation. Scenario testing may also provide an invaluable way to test the robustness of the income plan to significant health shocks, extreme longevity, or extreme market shocks, as suggested in Curtis (2006). While simulations provide probability distributions over the resulting outcomes, Curtis argues that retirement planning is more about being prepared for possibilities than probabilities.

The underlying asset return assumptions guiding the analysis should not simply be based on historical data averages. The practice of using historical averages as inputs to simulate stock and bond returns must stop. Return assumptions should be calibrated to match current market conditions, including current bond yields and a reasonable equity premium. With low bond yields at present, some readers may view using current conditions in long-term forecasts as too pessimistic. But with sequence of returns risk, what happens in the early part of retirement matters a great deal more than what happens later. Even if conditions normalize with higher real bond yields in 10 or 15 years, that may provide only minor relief to those retiring today. Wealth depletion in the early retirement period will be hard to overcome. 
Relatedly, data assumptions must be consistent across all product categories. This is a problematic aspect in various existing analyses. It is a mistake to use both current quotes for SPIA payout rates and historical data averages to guide stock and bond market returns. Such an approach will disadvantage SPIAs, as current bond yields and market conditions used to price annuities are much lower than the historical averages guiding the simulations for systematic withdrawals.

The fees associated with different products and categories must also be consistent. We cannot use a high-cost version of one strategy and a low-cost version of another strategy. Assumptions must be connected to what is reasonably available and expected to be used by a client. Fee assumptions should be stated prominently and readers must be able to see that they are applied in a consistent manner across strategies. Inconsistent fees could too easily lead to predetermined outcomes in favor of a particular strategy. Nevertheless, subjective decisions must be made about what are appropriate and consistent fees, and reasonable minds may disagree. The cumulative impacts of compounding even small differences in fees can be quite dramatic over time, making this a very important matter.

Two approaches to modeling retirement income strategies include investigating the best way to achieve a fixed spending pattern, or comparing variable spending patterns supported by different strategies. Though it is common to analyze retirement consumption paths which remain fixed in inflation-adjusted terms for as long as wealth remains, such spending strategies are suboptimal. Spending should adjust to some degree in response to market returns and survival probabilities, and the appropriate level of adjustments relates to the flexibility of the retiree. Survival probabilities may be used as weights on future outcomes, or a fixed horizon or planning age (such as life expectancy plus a reserve, or a fixed age such as 95, 100, or 105) is needed. Use of survival probabilities or low planning ages imply greater flexibility for future spending reductions as less weight, and thus less importance, is placed on outcomes (such as wealth depletion) in the distant future.

Another matter relates to building a floor, or at least having funds readily available to build a floor. Is there any effort to either lock-in lifetime flooring to protect from longevity risk or to monitor the amount of flooring that could be purchased as the portfolio fluctuates and take action to lock in flooring if the portfolio falls too low? Or is the portfolio left exposed depletion? Creating flooring does not necessarily require building a build ladder or purchasing annuitized products, but for practical purposes it requires vigilance to lock in some amount of client-identified minimal needs before it becomes too late in the event of a market drop.

Other important issues include behavioral and psychological concerns and needs of clients, the need for an emergency fund, and issues related to taxes and estate planning. 
Uncertain health care spending shocks are also an important concern with implications for precautionary savings, flexibility for assets, annuitization, and long-term care insurance. The client's entire balance sheet (including financial, social, and human capital) must be used to best match assets to spending goals. Plans should be revisited to allow for changing needs. For instance, attitudes about minimally acceptable and desired spending levels may evolve in unexpected ways. On the other hand, the gradual cognitive declines experienced with aging suggest importance for building a clear plan from the outset. It is also essential to incorporate the needs of advisors to earn a living when they provide recommendations.

A final matter is how to best evaluate competing alternative strategies. Clients will likely wish to be actively involved in choosing a strategy, which calls for using simple risk metrics which effectively highlight the tradeoffs between various goals. Clients are unlikely to accept black box solutions. However, the problem remains as for how to best represent the distribution of outcomes with a few summary statistics, such as failure rates or the amount of bequest in the median outcome. These simple measures do not incorporate all of the available information about the distribution of outcomes. At the same time, clients may feel overwhelmed if too much information is provided. The next section provides greater detail on evaluation measures.

\section{Evalution Criteria for Retirement Income Strategies}

We now have available numerous criteria to evaluate retirement income strategies. Following the game-of-life simulations described in Markowitz (1991), the evaluation criteria are generally applied to the resulting distributions from Monte Carlo simulations for capital market returns and/or individual ages of death. Historical simulations and scenario testing are also popular. By simulating a wide variety of conditions in retirement, the criteria measure key aspects from the distribution of retirement outcomes to so that clients and advisors can decide on a retirement income strategy that best balances the competing tradeoffs and needs of the client.

Evaluation criteria can be categorized into one of three general groupings: (1) measures to maximize spending on the downside for bad luck scenarios resulting in harsh postretirement conditions, (2) measures to maximize the overall or upside spending, and (3) measures of remaining financial assets which can be left as a bequest. Clients will place different importance on these groupings, and they are all important as retirement income strategies incorporate more complexities such as variable spending and diminishing marginal value provided by additional spending.

\section{Measures of Downside Spending}


The classic evaluation tool for traditional safe withdrawal rate studies is failure rates, or their corresponding success rates. For constant inflation-adjusted withdrawals, failure rates represent the percentage of simulations in which wealth is depleted before the end of the retirement period, whether that is a fixed time horizon or the end of the simulated lifetime, for various withdrawal rate and asset allocation strategies. Failure rates have several deficiencies though: they are not useful for strategies which partially allocate to guaranteed income sources or which use flexible withdrawals, in part to avoid wealth depletion, and they do not measure the magnitude of failure.

Milevsky (2009) and Milevsky and Macqueen (2010) describe "product allocation" as how to optimally allocate retirement wealth among systematic withdrawals, SPIAs, and variable annuities with guarantee riders. For guaranteed income sources, Milevsky creates the Retirement Sustainability Quotient (RSQ) as the portfolio success rate times the fraction of income taken from a volatile portfolio plus the fraction of annuitized income. Success for the portfolio alone is not a sufficient measure, since guaranteed income sources will be available even after the portfolio is depleted. Retirement sustainability can be improved by annuitizing more assets, lowering the withdrawal rate, and adjusting the portfolio asset allocation to minimize the failure probability for a given withdrawal rate.

Two ways to incorporate the magnitude of failure are to measure the amount of funds needed to maintain the desired spending level after wealth depletion, and to measure the number of years without remaining wealth at the end of the retirement period. Tomlinson (2012) provides an example of the former, while Malhotra (2012) provides an example of the latter. These measures adapt less well to variable withdrawal strategies.

As for a measurement tool which can capture downside, measure the magnitude of the downside, and allow for variable withdrawal strategies, I suggest summing over each year of retirement any amounts whereby spending falls below a minimally acceptable floor. The outcome measure could be the sum of these income shortfalls, or a figure could be constructed to show the percent of scenarios in which the minimum acceptable spending level is breached as well as the average and maximum amount of the breach for each retirement year.

Another possible downside measure is the lowest spending level of any year in the retirement period. Malhotra (2012) defines several other possibilities as well, including the percentage deviation of income from its starting level in the worst market decline across the simulations, and the percentage of simulations in which income falls by at least $40 \%$ from its starting level.

Measures of Upside Spending 
Total or average spending over the retirement period provides a simple measure which incorporates more aspects of spending than only the downside. Average spending can be calculated with equal weights for all years in the retirement period, or survival probabilities can be applied to spending in each year, resulting in greater importance for the spending in early retirement, and a preference toward strategies which frontload spending.

Another measure, utility maximization, is sometimes classified as a distinct approach. But this distinction is artificial, as any outcome measure implicitly includes an underlying utility function. Utility maximization is about translating spending amounts into the value they provide. More is better than less, but there are diminishing returns to the utility value of increased spending. Whereas average spending treats the marginal value of additional spending as linear, with utility maximization the value of spending is treated as a curve in which increased spending provides positive but diminishing gains in value. Utility maximization places greater emphasis on avoiding spending shortfalls below a clientidentified minimum floor, as utility can plummet deep into the negative range in such circumstances. Low spending is not desirable, but the impact and the willingness to trade more spending now for the potential for reduced spending later depends on the risk aversion and spending flexibility of the client. Less flexible retirees will be more attracted to the idea of spending less now to maintain a stronger reserve of funds for future spending. The usual way for utility outcomes to be presented is as the expected or mean utility for each simulated spending path.

\section{Measures of Bequests}

A common way to measure bequests is the average bequest value at the end of the retirement period, or as the sum of remaining wealth weighted by the probability of death for each year of retirement. Milevsky defines "Financial Legacy Value" (FLV) as the average bequest value at death for the strategy across the Monte Carlo simulations. The FLV can be increased by annuitizing less assets, lowering the withdrawal rate, increasing the stock allocation, or buying life insurance.

By connecting bequests to a downside spending measure, Milevsky (2010) and Huang, Grove, and Taylor (2012) develop what the latter calls an Efficient Income Frontier (EIF) for Retirement. Spending less will raise both sustainability and the legacy value. With a low enough withdrawal rate, annuitization is not necessary because it will lower the legacy value with only the slightest increase in the already high sustainability. With a high withdrawal rate, the retirement plans may not be realistic or sustainable, and the legacy value will be quite small either way, but annuitization will at least help increase sustainability somewhat from an already low level. For a given withdrawal rate, there tends to be a tradeoff between sustainability and legacy. Annuitizing more assets means 
increasing sustainability but lowering the legacy value. Increasing the stock allocation may lessen sustainability for low withdrawal rates, but it will increase the legacy value. Clients express their views about desired income, sustainability, and legacy by choosing an appropriate point on the income frontier, and each point has a corresponding asset and product allocation.

\section{Next Steps}

With this overview of retirement income building blocks, best practices for modeling retirement income strategies, and descriptions of key retirement outcome measures, the stage is set to build a more complete framework for evaluating retirement income strategies.

\section{References}

Ameriks, John, Robert Veres, and Mark J. Warshawsky. 2001. "Making Retirement Income Last a Lifetime." Journal of Financial Planning 14, 12 (December) 60-76.

Basu, Somnath. 2005. "Age Banding: A Model for Planning Retirement Needs.” Journal of Financial Counseling and Planning 16, 1: 29-36.

Bengen, William P. 2006. Conserving Client Portfolios During Retirement. Denver: FPA Press.

Bodie, Zvi, and Michael J. Clowes. 2003. Worry-Free Investing: A Safe Approach to Achieving Your Lifetime Financial Goals. Upper Saddle River, New Jersey: Financial Times Prentice Hall.

Curtis, Robert. 2006. "Monte Carlo Mania." In Retirement Income Redesigned: Master Plans for Distribution, Harold Evensky and Deena B. Katz (eds). New York: Bloomberg Press.

Evensky, Harold. 2006. "Withdrawal Strategies - A Cash Flow Solution.” In Retirement Income Redesigned: Master Plans for Distribution, Harold Evensky and Deena B. Katz (eds). New York: Bloomberg Press.

Guyton, Jonathan T. 2004. "Decision Rules and Portfolio Management for Retirees: Is the 'Safe' Initial Withdrawal Rate Too Safe?" Journal of Financial Planning 17, 10 (October): 54-62.

Huang, Dylan W., Matthew M. Grove, and Todd E. Taylor. 2012. "The Efficient Income Frontier: A Product Allocation Framework for Retirement." Retirement Management Journal 2, 1 (Spring): 9-22.

Huebscher, Robert. 2011. "The Simplest, Safest Withdrawal Rate.” Advisor Perspectives (August). 
http://advisorperspectives.com/newsletters11/The_Simplest_Safest_Withdrawal_ Strategy.php

Huxley, Stephen J., and J. Brent Burns. 2005. Asset Dedication: How to Grow Wealthy with the Next Generation of Asset Allocation. New York: McGraw-Hill.

Malhotra, Manish. 2012. "Retirement Income Compendium." Income Discovery (February 6). http://www.incomediscovery.com/research.html

Markowitz, Harry M. 1991. "Individual versus Institutional Investing." Financial Services Review 1, 1: 1-8.

Milevsky, Moshe A., and Alexandra C. Macqueen. 2010. Pensionize Your Nest Egg: How to Use Product Allocation to Create a Guaranteed Income For Life. Mississauga, Ontario: John Wiley \& Sons.

Milevsky, Moshe A. 2009. Are You a Stock or a Bond? Create Your Own Pension Plan for a Secure Financial Future. Upper Saddle River, New Jersey: Pearson Education.

Pfau, Wade D. 2011a. "Safe Savings Rates: A New Approach to Retirement Planning over the Life Cycle.” Journal of Financial Planning 24, 5 (May): 42-50.

Pfau, Wade D. 2011b. "Retirement Withdrawal Rates and Portfolio Success Rates: What Can the Historical Record Teach Us?" Retirement Management Journal 1, 2 (Fall): 49-55.

Reichenstein, William, and William Meyer. 2011. Social Security Strategies.

Shankar, S. Gowri. 2009. "A New Strategy to Guarantee Retirement Income Using TIPS and Longevity Insurance.” Financial Services Review 18, 1(Spring): 53-68.

Tomlinson, Joseph A. 2012. "A Utility-Based Approach to Evaluating Investment Strategies." Journal of Financial Planning 25, 2 (February): 53-60.

Zwecher, Michael J. 2012. "Mike Zwecher: They Each Get Only One Whack at the Cat." Retirement Researcher Blog (April 12). http://wpfau.blogspot.com/2012/04/mikezwecher-they-each-get-only-one.html 